\title{
Distribution of Candidatus Liberibacter asiaticus in Citrus and the Asian Citrus Psyllid in Texas Over a Decade
}

\author{
Mamoudou Sétamou, ${ }^{1, \dagger}$ Olufemi J. Alabi, ${ }^{2, \dagger}$ Madhurababu Kunta, ${ }^{1}$ Jon Dale, ${ }^{3}$ and John V. da Graça ${ }^{1}$ \\ ${ }^{1}$ Texas A\&M University-Kingsville Citrus Center, Weslaco, TX 78599 \\ ${ }^{2}$ Department of Plant Pathology \& Microbiology, Texas A\&M AgriLife Research \& Extension Center, Weslaco, TX 78596 \\ ${ }^{3}$ Texas Citrus Pest \& Disease Management Corporation, Mission, TX 78572
}

\begin{abstract}
Huanglongbing (HLB, citrus greening disease) in the major citrusproducing states of the United States is associated with Candidatus Liberibacter asiaticus (CLas), which is vectored by the Asian citrus psyllid (ACP). Surveys were conducted in Texas from 2007 to 2017 to assess the prevalence and titer of CLas in ACPs and citrus trees. ACP and citrus leaf tissue samples were collected from suspect trees in residential areas and commercial groves (orchards) and assayed for CLas by quantitative PCR. CLas detection in ACPs (2011) preceded that of citrus trees (2012) by several months. Annual incidences of CLas-positive ACPs and leaf tissue followed an exponential growth pattern over the survey period, varying from 0.03 to $28.7 \%$ in ACPs and 0.6 to $36.5 \%$ in citrus trees.

$40 \%$ of commercial groves and residential sites, respectively, by 2017 . Seasonal variations were observed in the incidences of CLas-positive ACPs and citrus trees such that significantly more CLas-positive ACPs and trees were recorded during the fall and winter of a given year relative to the hot summer. A temporal analysis of the class distribution of cycle threshold values revealed a trend of increased bacterial accumulation in ACPs and trees over time, with the trend more pronounced for the former than the latter host type. These findings provide a comprehensive insight into the ongoing CLas/HLB epidemic in Texas, with potential lessons for California and other citrus-producing areas where the disease is not yet established.
\end{abstract} There was a significant and positive relationship between the monthly incidences of CLas-positive ACP and leaf tissue samples. The proportion of HLB detection sites also increased with time, reaching 26 and
Keywords: Asian citrus psyllid, asiaticus, citrus, Candidatus Liberibacter, citrus greening disease, epidemiology, HLB, Huanglongbing
Citrus (Citrus spp.; family Rutaceae) is an ancient crop cultivated primarily for its edible fruits, often consumed fresh or juiced. Citrus fruits are also processed into secondary products such as jams, jellies, and several items of confectionery. The leaves of certain Citrus species have culinary benefits, and the fruit peels serve as sources of essential oils. The establishment of a commercial citrus grove (or orchard) is considered a lifelong investment because of the tree's perennial growth habit. Unfortunately, this growth habit coupled with the sessile nature of trees in general favors the accumulation and perpetuation of multiple infectious disease-causing agents within the plant, including those of fungal, bacterial, and viral etiologies. These infectious agents also benefit from citrus production horticultural practices such as clonal propagation, grafting, and topworking to persist and evolve. Notable among the scores of documented diseases of citrus are the bacterial citrus canker disease, caused by Xanthomonas citri subsp. citri; the viral citrus tristeza disease, caused by Citrus tristeza virus; the fungal citrus black spot, caused by Phyllosticta citricarpa; the root and foot rot, caused by oomycetes Phytophthora spp.; and the bacterial huanglongbing (HLB; citrus greening disease), associated with Candidatus Liberibacter spp. (Timmer et al. 2000).

HLB is currently the most destructive disease among the many biotic production constraints of citrus (Bové 2006; da Graça et al. 2016). Although HLB was widely believed to have originated in

${ }^{\dagger}$ Corresponding authors: M. Sétamou; Mamoudou.Setamou@tamuk.edu, and O. J. Alabi; alabi@tamu.edu

Funding: We express our sincere gratitude to USDA-APHIS-PPQ for funding through the Citrus Commodity Pest Survey Corporative Agreements.

*The $\boldsymbol{e}$-Xtra logo stands for "electronic extra" and indicates that one supplementary figure is published online.

The author(s) declare no conflict of interest.

Accepted for publication 4 November 2019

(C) 2020 The American Phytopathological Society
China (Bové 2006; da Graça 1991), Beattie et al. (2008) present a strong case for the Indian subcontinent as the more likely source, and the disease is now widespread in many parts of the world, including Asia, Africa, South America, and the United States, gravely threatening global citrus production. HLB-associated losses in Florida are estimated at several billions of U.S. dollars since the disease was first detected in the state in 2005 (Singerman et al. 2017). Because of the lack of effective control measures, Florida's \$9-billion citrus industry is fighting for survival from the crippling effects of HLB-associated losses. From its pre-HLB era of being the top citrus producer in the United States, Florida is now second to California because of the HLB epidemic.

The most prevalent phloem-inhabiting alphaproteobacterium identified in HLB-affected citrus trees in the United States is Candidatus Liberibacter asiaticus (CLas) (Gottwald 2010). The phloem colonization of CLas may disrupt the transport of photosynthates, leading to gradual tree decline and fruit drop. CLas is transmitted by the phloem-feeding Asian citrus psyllid (ACP), Diaphorina citri Kuwayama. The ACP was first detected in the United States in Florida in 1998 (Halbert and Manjunath 2004) and subsequently in the two other leading citrus-producing states: Texas in 2001 (French et al. 2001) and California in 2008 (Grafton-Cardwell et al. 2013). The ACP is also present in other citrus-producing areas of the United States and its adjoining islands, indicating the invasive nature of this pest insect (Grafton-Cardwell et al. 2013). HLB was confirmed in Florida in 2005 (Halbert 2005), and multiyear surveys showed that the disease became pandemic in the state within 5 years (Gottwald 2010). In addition to the aforementioned direct HLB-associated economic losses in Florida, indirect losses caused by the disease include increased production costs, mainly for intensive pesticide input for ACP control, and enormous investments by the industry and state and federal government on research for HLB therapeutics and ACP control.

The citrus industry in Texas is located in the three southernmost counties of the state: Hidalgo, Cameron, and Willacy, collectively referred to as the Lower Rio Grande Valley (LRGV) area (Supplementary Fig. S1). Citrus production is an integral part of the culture and heritage of the residents of the LRGV. The Texas citrus industry encompasses 
about 1,500 commercially managed blocks covering about 12,146 ha, and 750,000 to $1,000,000$ trees ( 20 to $25 \%$ of the total commercial citrus tree population in the state) are estimated to be present in residential settings (Arteaga 2017). Commercial citrus production in Texas is dominated by grapefruit (Citrus $\times$ paradisi Macfad) and sweet orange $(C$. sinensis (L.) Osbeck), accounting for 65 and $30 \%$ of total acreage, respectively (Supplementary Fig. S1). The remaining 5\% consists of limes and lemons. Unlike Florida, where approximately $95 \%$ of all oranges grown in the state are processed for juice (USDA/NASS 2016), citrus production in Texas is destined primarily for the fresh fruit market. The varietal composition of dooryard trees largely mirrors that of commercial groves, with grapefruit and sweet orange being the dominant species. However, the diversity of citrus species in residential settings in Texas is greater than that of commercial groves (Arteaga 2017). Notably, commercial groves and residential citrus are intermingled in the LRGV, thus constituting a contiguous ecosystem.

After the first report of HLB and CLas in Florida in 2005 (Halbert 2005), efforts were initiated to survey for CLas in citrus trees and ACPs in commercial groves and residential sites in Texas. The primary goals of this HLB mitigation effort in Texas were to identify CLas-infected trees as early as possible and implement the recommended three-pronged approach for disease management (Bové 2014). The objectives of this study were to assess the prevalence of CLas in ACPs and citrus trees in Texas from 2007 to 2017 and to determine the factors influencing the spatial and temporal dynamics of the bacterium under Texas growing conditions.

\section{Materials and Methods}

Survey for CLas in citrus trees and ACPs. The study was conducted in commercial citrus groves and residential sites across the Texas citrus industry (Supplementary Fig. S1). The survey was designed such that the entire Texas citrus industry (about 12,146 ha) was divided into grids of $2.59 \mathrm{~km}^{2}$ each and the number of blocks per grid enumerated. A block is a solid unit planting of citrus whose boundaries are delineated by roads and irrigation or drainage canals. Twenty-five percent of the blocks in each grid were surveyed on a 1 -year cycle in an additive manner such that all blocks in the entire industry (about 1,500 blocks) were surveyed over four cycles (i.e., a 4-year period). The survey routine was then restarted in the fifth year. Thus, each block was surveyed at least twice over the 10-year study period. The surveys in residential sites followed an independent grid system whereby the entire LRGV was divided into $2.59-\mathrm{km}^{2}$ grids. Twenty-five percent of all grids were surveyed each year in an additive manner, but only 25 randomly selected residential properties with dooryard citrus were surveyed per grid. All residential grids were surveyed over a 4-year period, after which the routine was restarted. Thus, both survey schemes ensured that the obtained samples were spatially representative of commercial and residential citrus in the LRGV.

A hierarchical structure was implemented for each commercial grove survey. Initially, the border trees, that is trees located in the grove perimeter, were examined for HLB-related symptoms such as yellow veins, corky veins or leaf mottling, extensive twig dieback, and small and lopsided fruit with or without color inversion (Fig. 1). Two surveyors, one on each side of the tree canopy, worked in tandem and walked down the row while carefully examining the tree from the outer canopy inwards. In the residential sites, the surveyors examined the trees for HLB-related symptoms, after which suspect trees were flagged and their Global Positioning System coordinates, name of surveyors, and survey date were recorded. Leaf tissue samples with any of the HLB-related symptoms were then collected in labeled self-sealing bag. Any tree that tested positive for CLas during a survey cycle was excluded from sampling in subsequent surveys.
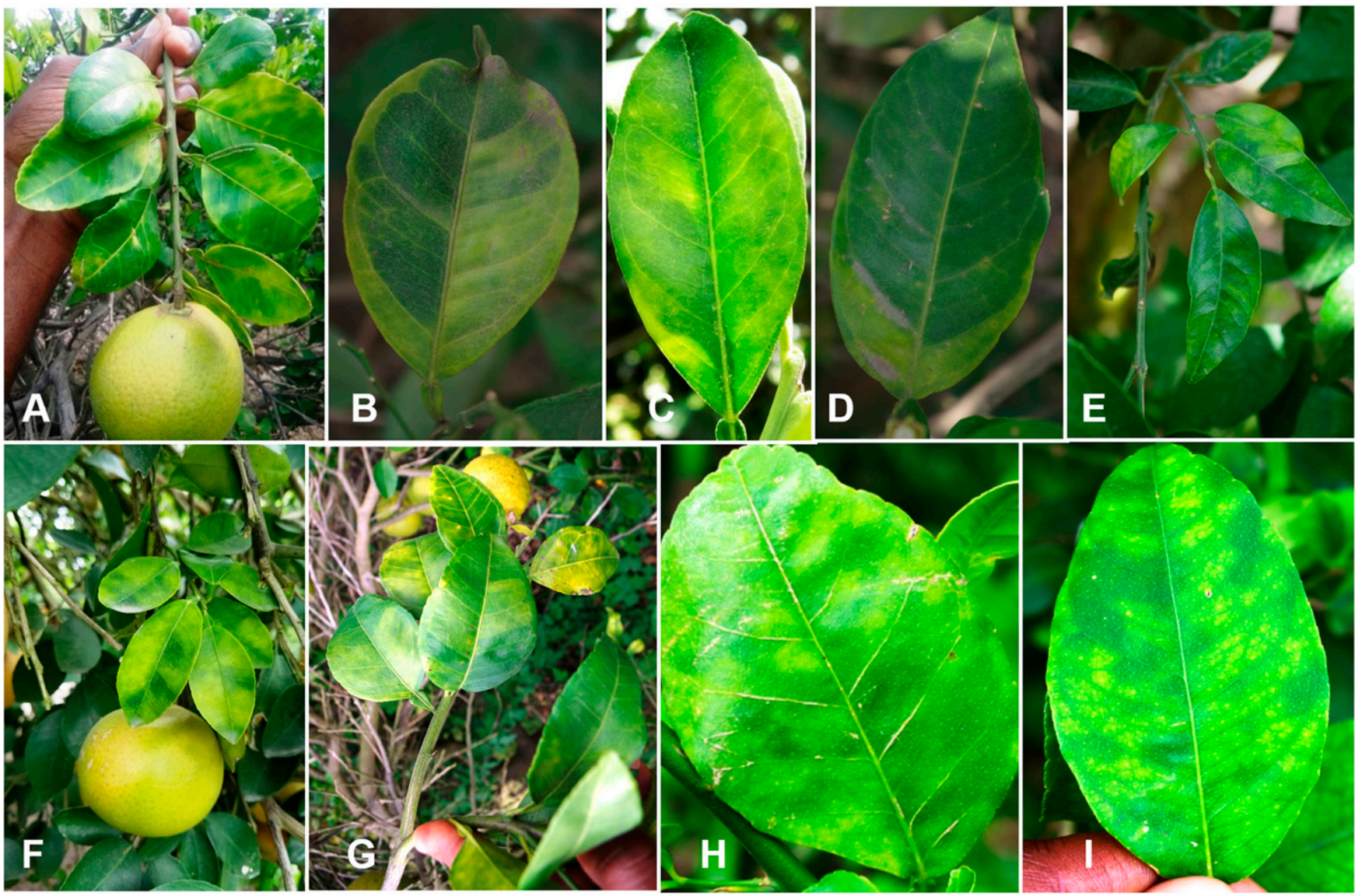

Fig. 1. Diverse huanglongbing (HLB) symptom types on the different citrus varieties including $A$ to $D$, sweet oranges, $E$, tangerines, $F$ and $G$, grapefruit, $H$, limes, and $\mathbf{I}$, lemon Some instances of HLB-associated misshapen fruit symptoms were also observed, particularly on sweet orange and grapefruit trees. 
The sampled commercial and residential trees were also examined for the presence of ACP nymphs and adults. In commercial groves, a tap sampling method was used to dislodge adults onto a white moistened plastic board (Hall and Hentz 2010). Adult ACPs from residential trees were collected with an aspirator. Any fourth to fifth ACP instars found on the trees were also collected with a camel hair brush. The ACP individuals were preserved in labeled plastic vials containing $95 \%$ alcohol.

The ACP and leaf tissue samples were transported the same day to the laboratory on ice packs and kept in a refrigerator until processed, generally within 2 to 5 days. All survey data were input into a database maintained at the Texas A\&M University-Kingsville Citrus Center in Weslaco, Texas. A quantitative PCR (qPCR)-positive CLas detection in ACP or leaf tissue border survey samples from a commercial grove triggered an intensive whole grove survey whereby all the trees (with or without HLB-related symptoms) in the CLaspositive grove were sampled and tested. However, the intensive grove survey protocol was discontinued by the industry from summer 2014 onward.

qPCR analysis. Total DNA was isolated from $200 \mathrm{mg}$ of finely chopped midrib and petiole tissues excised from the leaf samples. DNA extractions were made from ACP adults or nymphs. CLas and Candidatus L. americanus were assayed in DNA samples via multiplex real-time PCR assays performed on a thermal cycler and analyzed as previously described (Li et al. 2006, 2008a, b). All reactions contained known positive and negative control DNA samples and nontemplate water control. A sample was considered CLaspositive based on a regulatory cycle threshold $(\mathrm{Ct})$ value of $\leq 37$.

Weather data. Climatic variables were retrieved from a weather station located in Weslaco, Hidalgo County, Texas, which represents the geographic midpoint of the commercial citrus industry (http:// southtexasweather.tamu.edu/). They include the air temperature (in ${ }^{\circ} \mathrm{C}$ ), percentage relative humidity, wind speed (in kilometers per hour), soil temperature (in ${ }^{\circ} \mathrm{C}$ at $15 \mathrm{~cm}$ depth), and total rainfall (in millimeters). The average monthly data for each variable were summarized from January 2007 to December 2017. The heat index (i.e., the apparent temperature) was also calculated via the formula described by the National Weather Service Weather Prediction Center (https://www.wpc.ncep.noaa.gov/html/heatindex.shtml). These variables were included as explaining descriptors in stepwise regression to determine factors influencing the spatial and temporal dynamics of CLas under Texas growing conditions.

Statistical data analysis. Analysis of the progress of CLaspositive groves over time was based on yearly (January to December)

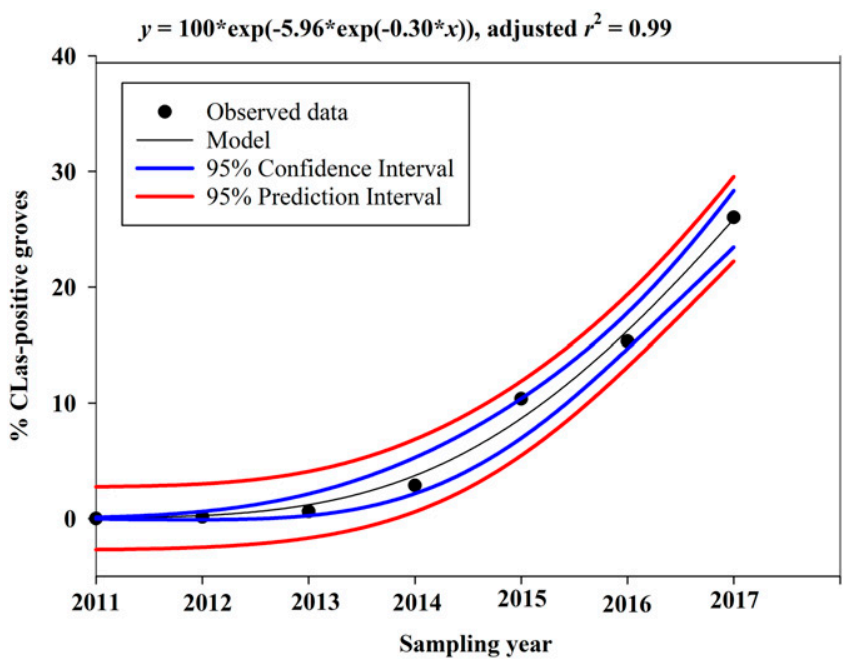

Fig. 2. Progression of citrus groves that tested positive for Candidatus Liberibacter asiaticus (CLas) from 2011 to 2017 in Texas. Testing of Asian citrus psyllid and leaf tissue samples collected during the surveys (Table 1) for CLas by quantitative PCR did not result in a positive detection from 2007 to 2010 . cumulative numbers of groves with at least one infected tree present. The Gompertz model:

$$
\left(y[t]=100 * \exp \left[-b^{*} \exp (-r t)\right]\right)
$$

was fitted to the cumulative percentages of infected groves out of the total number of commercial groves in the LRGV, where $b$ is a parameter related to the initial grove incidence, $r$ is the annual progress rate of CLas-positive groves, and $t$ is the time in years $(t=0$ for 2011). The monthly and yearly incidences and the mean $\mathrm{Ct}$ values of CLas-positive ACP and leaf tissue samples were calculated. The Gompertz model was also used to describe the temporal variations of CLas incidences in ACPs and citrus trees, and a linear regression analysis was performed to determine the relationship between the monthly CLas incidences in ACPs $(x)$ and leaf tissue $(y)$. The yearly distributions of arbitrary $\mathrm{Ct}$ value classes $(\mathrm{Ct}<27$, $\mathrm{Ct}=27$ to $32, \mathrm{Ct}>32$, corresponding to high, moderate, and low bacterial titers, respectively) were compared via a log-likelihood ratio test. The yearly distribution of $\mathrm{Ct}$ values obtained from CLas-positive ACP and leaf tissue samples over the study period were determined with box plots. Stepwise regression analyses were performed to evaluate the effects of climatic factors and CLas biological data (percentage ACP or tree infection and $\mathrm{Ct}$ values) on the incidences of CLas in citrus trees and ACP populations. Finally, we predicted the length of time necessary from the first CLas incidence in Texas to attain the saturation point, that is, a point when CLas incidence is recorded in all commercial groves in the state based on the Gompertz model. All analyses were run in XLSTAT statistical analysis software version 2019.1.2 (XLSTAT 2017).

\section{Results}

HLB symptoms and disease prevalence. The first confirmation of CLas infection in citrus trees occurred in 2012 in a sweet orange (cultivar Valencia) grove located in Hidalgo County (da Graça et al. 2015; Kunta et al. 2012; Sétamou et al. 2012). The HLBaffected trees showed typical foliar symptoms of blotchy mottle and yellow veins (Fig. 1A to D). Over the 10-year survey period, diverse HLB symptom types were recorded on the leaves of different citrus varieties including sweet oranges (Fig. 1A to D), tangerines (Fig. 1E), grapefruit (Fig. 1F and G), limes (Fig. 1H), and lemon (Fig. 1I). Some instances of HLB-associated misshapen fruit symptoms were also observed particularly on sweet orange and grapefruit trees (Fig. 1A and F), although fruit symptoms were less prevalent. From a single HLB-affected commercial grove and a residential site in Hidalgo County in January 2012, HLB prevalence grew exponentially through time and reached about $26 \%$ of commercial groves (Figs. 2 and 3A) and about $40 \%$ of residential sites (Fig. 3B) by December 2017. The Gompertz model accurately described the progression of CLas detection in commercial groves over time, with strong goodness-of-fit (adjusted $r^{2}=0.99$; Fig. 2). The annual rate of progression of CLas-infected groves was estimated at $0.30 /$ year $^{-1}$ (Fig. 2). An overlap of positive detection sites of both ecologies, commercial groves and residential sites, was observed (Fig. 3). Notably, we observed greater aggregation of CLas-positive trees around urban-grove interfaces (data not shown), suggesting that disease spreads in both ecologies directly influence each other. Some of the commonly observed attributes of the HLB-positive residential sites include the young age ( $\leq 5$ years) of the infected trees, year-long presence of flush shoots on the trees, and disproportionately high abundance of ACP life stages (data not shown). In contrast, trees in commercial groves were characterized by an average age of 15 years (range 1 to 36 years), cyclical presence of flush shoots (about 5 per year), and low ACP population densities, caused by the implementation of intensive industry-mandated psyllid control programs. To date, HLB detections have also been reported in 11 other counties across Texas (Aransas, Brooks, Calhoun, Fort Bend, Harris, Kennedy, Kleberg, Montgomery, Nueces, Starr, and Webb), whereas ACP occurs statewide. A link to an interactive map of HLB quarantine areas in Texas is available at https://www.texasagriculture.gov/RegulatoryPrograms/ PlantQuality/PestandDiseaseAlerts/CitrusGreening.aspx. 
CLas incidence in ACP and citrus trees. All ACP and leaf tissue samples collected from 2007 to 2010 (Table 1) tested negative for CLas by qPCR (Fig. 2). The first CLas detection was recorded in ACPs in 2011 with an incidence of $0.03 \%(21 / 7,002)$ (Table 1; Fig. 4A). All 7,370 leaf tissue samples tested in the same year were negative for CLas (Table 1; Fig. 4C), indicating an early detection of CLas in ACPs relative to leaf tissues. The first CLas-positive leaf tissue was confirmed in January 2012 from a commercial sweet orange grove (cultivar Valencia), several months after first detection in ACPs. In 2012, cumulative CLas incidence in ACPs (Fig. 4A) and citrus trees (Fig. 4C) sampled from both residential and commercial sites were $1.4 \%(168 / 11,992)$ and $0.61 \%(47 / 7,679)$, respectively. Annual percentages of CLas incidence in ACPs and citrus trees increased exponentially from the initial detection levels in both tissue types over the 10-year survey period (Fig. 4A and C). The annual rate of increase in overall CLas incidence was similar between ACPs $(y=100 * \exp [-19.31 * \exp (-0.39 * t)] ; F=246.41 ; d f=2,6 ; P<0.0001$; pseudo- $\left.R^{2}=0.98\right)$ and trees $(y=100 * \exp [-11.83 * \exp (-0.34 * t)]$; $F=114.14 ; d f=2,6 ; P<0.0001 ;$ pseudo- $R^{2}=0.96$ ) (Fig. 4A and $\mathrm{C}$ ), as shown by the overlapping confidence intervals (CIs) of both rates of increase (ACP CI $=0.29$ to 0.48 ; tree $\mathrm{CI}=0.22$ to 0.46). Additional analysis revealed peaks in CLas incidences in ACPs and citrus trees (Fig. 4B and D) during the fall and winter (September to March) and lower incidences during the summer (late May to July) under Texas growing conditions. The only exception was 2016, when CLas incidence in citrus trees peaked between June and August (Fig. 4D). Based on a simple regression analysis, a positive and direct relationship was observed between monthly CLas incidences in ACPs $(x)$ and leaf tissue $(y)(y=$ $\left.0.89 x+3.87 ; t=9.77 ; R^{2}=0.53 ; P<0.0001\right)$, indicating that each unit increase of CLas incidence in ACPs is equivalent to a 0.89 increase in trees.

Dynamics of CLas titer in ACPs and citrus trees. The mean $\mathrm{Ct}$ values of CLas-positive ACPs from 2011 to 2017 was 33.4 (range = 20.6 to 37 ) (Fig. 5A). However, the values ranged from 17.6 to 37 $($ mean $=25.6)$ in citrus leaf tissues during the same period (Fig. 5B). A temporal analysis of the class distribution of $\mathrm{Ct}$ values revealed consistently greater proportion of $\mathrm{ACP}$ and citrus trees with higher bacterial titer $(\mathrm{Ct}<27)$ over the years (Fig. 5C and D), with this trend more pronounced for ACP (log-likelihood ratio $G=84.30$, $d f=10, P<0.0001$; Fig. $5 \mathrm{~A}$ and $\mathrm{C}$ ) than leaf tissues (loglikelihood ratio $G=40.38, d f=8, P<0.0001$; Fig. 5B and D). A linear regression analysis of the yearly median $\mathrm{Ct}$ values through time indicated a significant downward trend for ACP $(y=35.18$ $\left.0.67 x ; t=2.91 ; R^{2}=0.62 ; P=0.02\right)$ compared with leaf tissue $\left(y=24.50+0.10 x ; t=0.44 ; R^{2}=0.07 ; P=0.67\right)$. Taken together, the results showed that that the psyllid accumulation of CLas is more time dependent than that of citrus trees, based on the more pronounced shifts in percentage across the $\mathrm{Ct}$ categories.

Factors regulating CLas incidence in ACPs and citrus trees. To understand the factors regulating CLas incidences in ACPs and citrus trees, we performed stepwise regressions to evaluate the effects of climatic factors and potential inoculum sources on both host types. The monthly CLas incidences in citrus trees were positively affected

Table 1. Yearly total number of Diaphorina citri and citrus leaf tissue samples tested $^{\text {a }}$ for the presence of Candidatus Liberibacter asiaticus (CLas) from 2007 to 2017 in Texas

\begin{tabular}{lrrrrr}
\hline & \multicolumn{2}{c}{$\begin{array}{c}\text { D. citri } \\
\text { (adults and nymphs) }\end{array}$} & & \multicolumn{2}{c}{ Citrus leaf tissue } \\
\cline { 2 - 3 } \cline { 5 - 6 } Year & Total & CLas-positive & & Total & CLas-positive \\
\hline $2007^{\mathrm{a}}$ & 36 & 0 & & 83 & 0 \\
2008 & 253 & 0 & & 401 & 0 \\
2009 & 18,000 & 0 & & 5,212 & 0 \\
2010 & 11,328 & 0 & & 5,310 & 0 \\
2011 & 7,002 & 21 & & 7,370 & 0 \\
2012 & 11,992 & 168 & & 7,679 & 47 \\
2013 & 17,103 & 185 & & 9,020 & 107 \\
2014 & 6,354 & 274 & & 17,402 & 1,623 \\
2015 & 3,978 & 225 & & 20,469 & 2,170 \\
2016 & 4,202 & 577 & & 10,483 & 1,824 \\
2017 & 2,122 & 741 & & 13,958 & 4,684 \\
\hline
\end{tabular}

${ }^{a}$ Insects and leaf samples were submitted to the U.S. Department of Agriculture (USDA) Animal and Plant Health Inspection Service laboratory in Gastonia for testing in 2007. From 2009 onward, all testing was performed at the USDA-certified Texas A\&M University-Kingsville Citrus Center laboratory.

A

B Residential sites

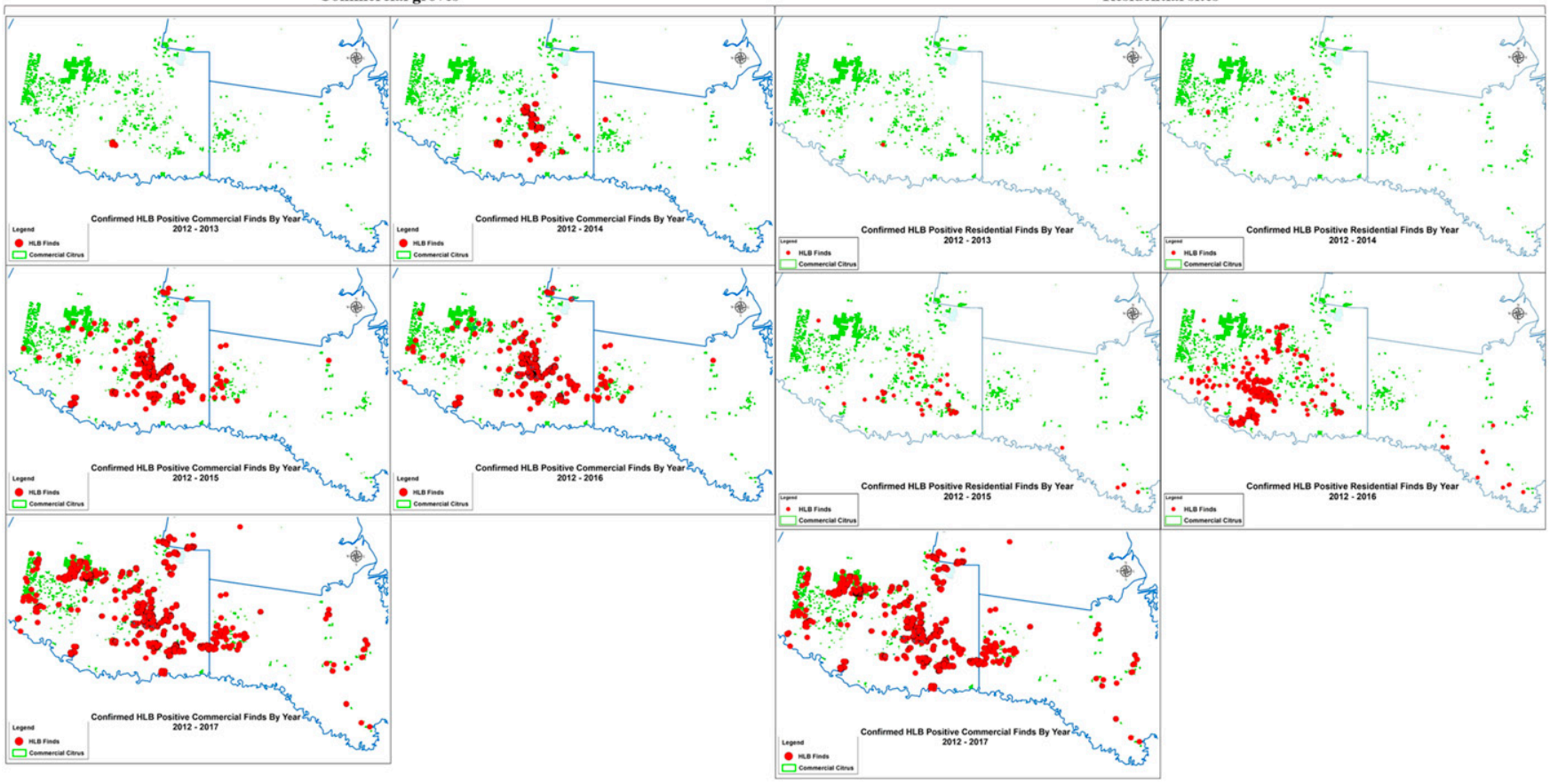

Fig. 3. Distribution maps of A, citrus groves and B, residential sites with trees tested positive for Candidatus Liberibacter asiaticus (CLas) from 2012 to 2017 in Texas. Areas shaded green = commercial citrus groves; red circles = CLas-positive sites. Blue lines represent county or international boundaries. Testing of Asian citrus psyllid and leaf tissue samples collected during the surveys (Table 1) for CLas by quantitative PCR did not result in a positive detection from 2007 to 2010. 
by total rainfall, the incidences of CLas-positive ACPs, and CLas titer in citrus leaf tissue (Table 2). In contrast, the CLas incidences in citrus trees were negatively affected by mean high temperature and percentage relative humidity (Table 2 ). The monthly CLas incidences in ACPs were positively affected by mean low temperature and the incidence of CLas-positive citrus trees (Table 2). In contrast, CLas incidences in ACPs were negatively affected by wind speed, total rainfall, and the heat index (Table 2). The results indicated that CLas prevalence is influenced by the presence of inoculum sources and certain environmental factors, in a hostdependent manner. The results also agree with observations derived from the LRGV climatic data that showed greater than the approximate optimal temperatures for the establishment of CLas in citrus plants (Gasparoto et al. 2012) and growth and development of ACPs (Liu and Tsai 2000) during the late spring and summer (Fig. 6).

Prediction of CLas spread in commercial groves. Using parameters derived from the Gompertz model, which showed an annual growth rate of 0.30 (Fig. 2), we developed a predictive model of CLas spread across commercial groves in the LRGV. The results showed that the speed of initial epidemic development was faster, with $50 \%$ of groves infected by 2018 to 2019 and $90 \%$ by 2024 to 2025 , and tapered onward with saturation (approximately 100\% prevalence of infection) reached by 2035 . Thus, the results indicated that it would take 24 years from the first confirmed incidence of CLas in Texas (2012) to reach the point of saturation (2035) whereby $100 \%$ CLas prevalence is recorded across the commercial citrus industry in the state (Fig. 7).

\section{Discussion}

After the first report of HLB in Florida in 2005, citrus growers and industry stakeholders in Texas were concerned about possible spread of the disease into the state and its potential negative impacts on the industry. The ACP was first reported in Texas in 2001 (French et al. 2001), and it became widespread across the LRGV by 2007 (da Graça et al. 2008, Sétamou et al. 2008). Therefore, after introduction CLas had the potential to rapidly become an epidemic in the commercial citrus production area via vectormediated spread. To limit the risk of HLB introduction into Texas and its spread, an assessment of possible pathways was made, and four mitigation efforts were implemented beginning in 2006. These were the initiation of an area-wide CLas detection program in ACPs and citrus trees in 2006, with the goal of early detection and elimination of infected trees; enactment of legislation in 2008 to prevent the importation of rutaceous host plants of ACP into Texas; a transition from traditional open-field nurseries to enclosed facilities with insect-resistant screens to mitigate the risk of planting materials serving as sources of CLas spread in 2012; and implementation of an area-wide ACP control program in commercial groves to reduce vector population densities starting in
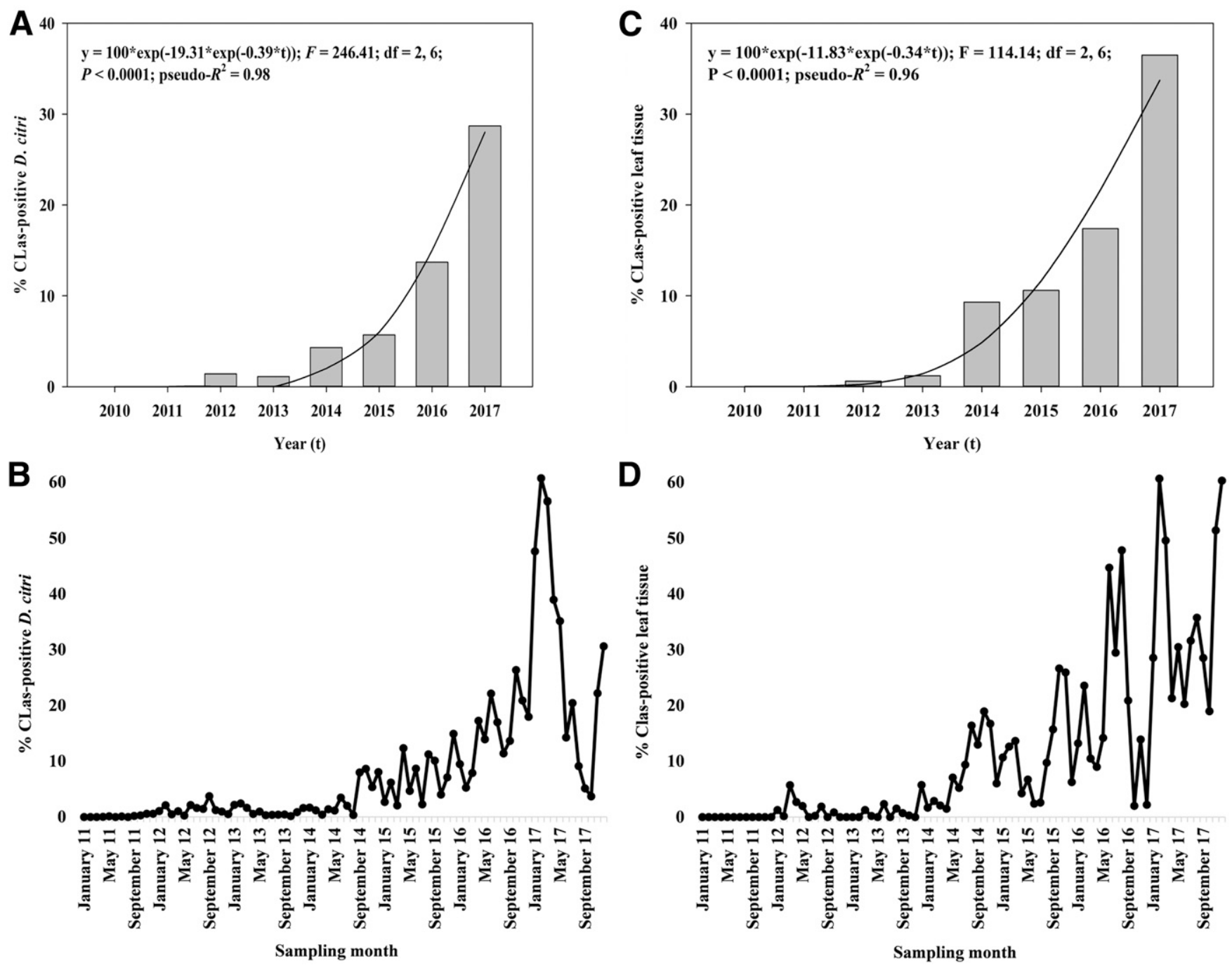

Fig. 4. Seasonal fluctuations of Candidatus Liberibacter asiaticus (CLas) incidence in A and B, Diaphorina citri and C and D, citrus trees sampled from commercial and dooryard citrus in Texas from 2011 to 2017 . Testing of Asian citrus psyllid and leaf tissue samples collected during the surveys (Table 1) for CLas by quantitative PCR did not result in a positive detection from 2007 to 2010 . 
2010. Despite these efforts, the first CLas-infected ACPs and citrus tree were confirmed in 2011 and 2012, respectively (Figs. 3 and 4), suggesting an inadvertent introduction of infected plant material or bacteriliferous ACPs before enforcement of the exclusionary measures. This and the subsequent CLas-positive detections triggered the removal of the infected trees and the implementation of both state and federally mandated quarantine measures as mentioned earlier. However, the infection foci continued to grow beyond the quarantine areas, indicating a continuous spread of the disease. Possible reasons include the ineffectiveness of the tree eradication measures, the persistence of vector-mediated spread despite implementation of the area-wide ACP control program, the influence of residential citrus, or a combination of all three. The ACP was not considered a pest of economic importance in Texas groves before HLB, and therefore no targeted control measures were implemented. Tree eradication relied on symptom-based sampling for CLas detection, hence the inherent risk of not sampling trees during the incubation period. Whereas the area-wide ACP control program was successfully implemented in commercial groves, residential citrus trees continued to be breeding sites and sources of ACP reinfestation, as previously documented for different invasive species (Alston and Richardson 2006; Gasparoto et al. 2018; Gavier-Pizarro et al. 2010). These situation-specific factors may explain the exponential growth of CLas incidences in ACPs and citrus trees and HLB prevalence over the study period. By 2014, most growers ceased removing confirmed CLas-positive trees in mature ( $\geq 7$ years) groves because of increased risks of disease spread and economic considerations. There is also the possibility that the trade of open-field nursery trees, exposed to HLB, facilitated disease spread within the LRGV and across the state before the new enclosed nursery regulation came into effect, as reported earlier (Alabi et al. 2014).

The spatial pattern of HLB-positive groves points to a clustering in the mid-Valley area (between interstate highways 69C and 69E; Fig. $3)$. An interesting feature of this section of the LRGV is that most commercial groves are interfaced with residential neighborhoods with abundant citrus trees in backyards. Coincidentally, most of the open-field nursery facilities were also located in this area, suggesting that these young trees may have been exposed to CLas infection before planting. In addition, we observed disproportionately higher ACP densities in the same area, which may be a consequence of frequent production of new flush shoots by these young nursery trees. Indeed, the retail nursery facilities implicated in HLB spread into Fort Bend, Harris, and Montgomery counties received plants from an open-field nursery facility in the mid-Valley area (Alabi et al. 2014), further supporting our observation. This finding underscores the role of nursery trade in facilitating both short- and longdistance CLas spread (Halbert et al. 2012) and the importance of their propagation in enclosed certified structures.

Analyses of $\mathrm{Ct}$ value classes obtained from CLas-positive ACPs and citrus trees point to an increased bacterial titer in both tissue types over time (Fig. 5). CLas is capable of replicating within ACPs and citrus trees after acquisition and infection, respectively (Ammar et al. 2016; Coletta-Filho et al. 2010; Inoue et al. 2009). It is also plausible that ACP-mediated reinfection of CLas-positive citrus trees would result in greater bacterial accumulation through time. Furthermore, because the analyzed ACPs are feral individuals, we cannot discount the possibility that a greater proportion of the tested insects acquired CLas as nymphs. Despite the observed increased bacterial
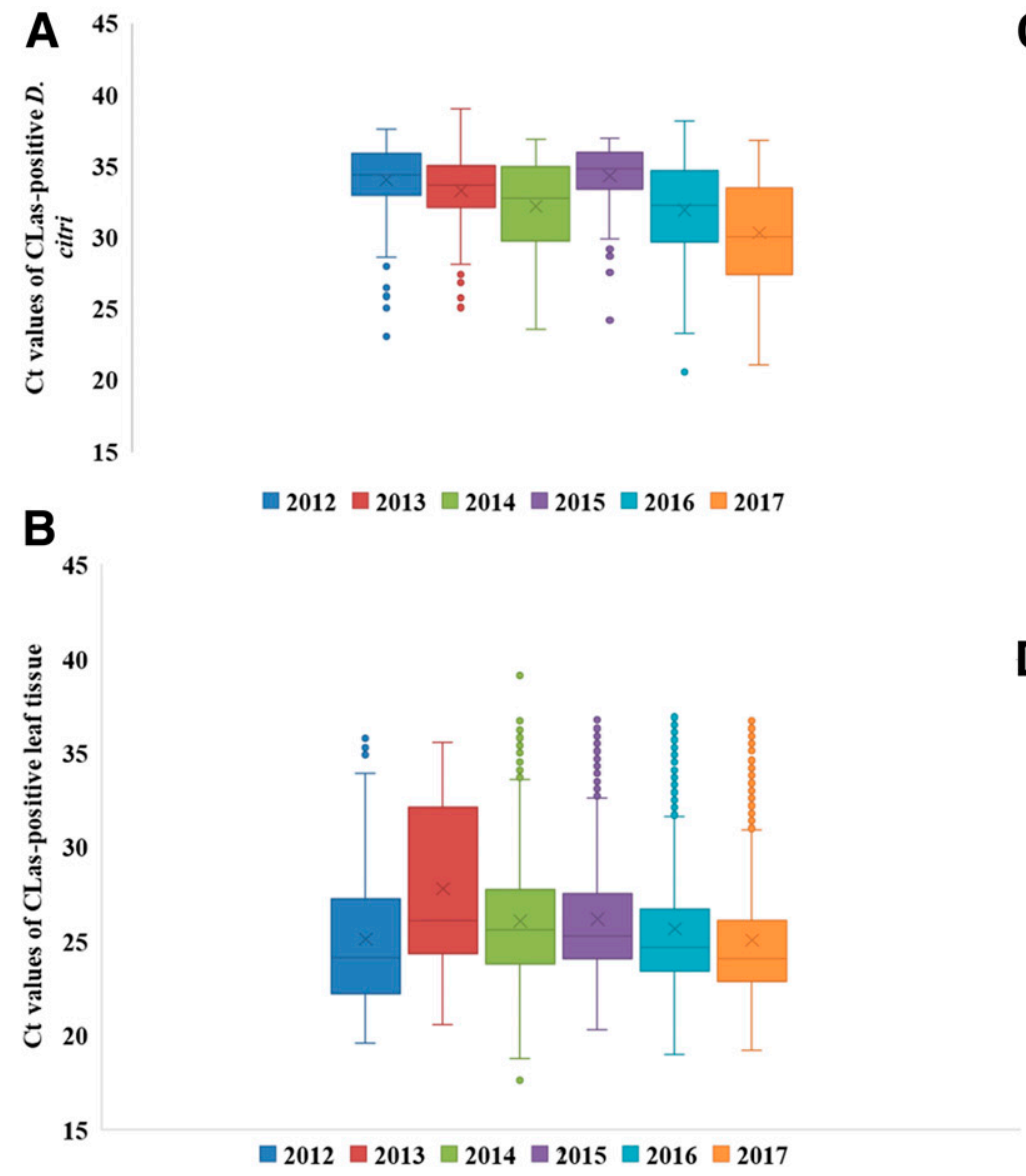
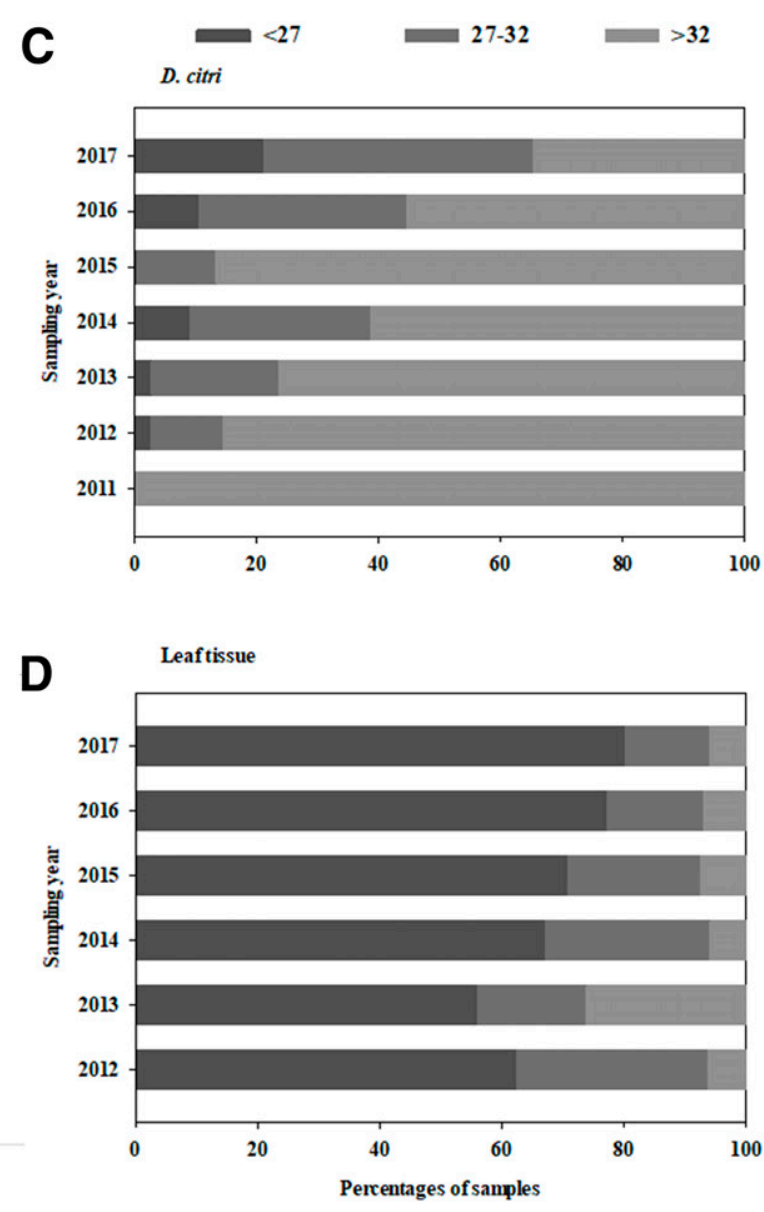

Fig. 5. A and B, Yearly and C and D, class distributions of Candidatus Liberibacter asiaticus (CLas) cycle threshold (Ct) values of positive Asian citrus psyllid (D. citri) and citrus trees in Texas. The arbitrary classes of Ct values correspond to high ( $<27)$, medium (27 to 32$)$, and low ( $>32)$ bacterial titers. Testing of Asian citrus psyllid and leaf tissue samples collected during the surveys (Table 1) for CLas by quantitative PCR did not result in a positive detection from 2007 to 2010. 
titer in ACPs over time, the higher mean $\mathrm{Ct}$ values in ACPs, corresponding to lower bacteria titers, relative to leaf tissue (Fig. 5) opens up the possibility that certain factors may be limiting bacterial accumulation and replication within ACP under Texas growing conditions. Among several considerations, we propose that the area-wide ACP management program in Texas contributes by limiting successful reproduction and development of ACPs in groves. It has been shown that CLas acquisition and replication in ACPs is more efficient in nymphs than in adults (Ammar et al. 2016). Therefore, the majority of our ACP catches in commercial groves probably acquired the bacterium on residential trees, where little or no vector management is implemented, before their migration into commercial groves because of the close interface between the two habitats in south Texas.

One of the often-neglected vertices of the disease triangle (or pyramid) is the environment. Climatic factors may modulate the host plant response to pathogen infection as well as vector-pathogen and vector-host interactions (Lewis-Rosenblum et al. 2015; Lopes et al. 2017; Velásquez et. al. 2018). Our stepwise regression analyses showed that whereas the monthly CLas incidences in citrus trees were positively affected by total rainfall, the incidences of CLaspositive ACPs, and CLas titer in citrus leaf tissue (Table 2), the converse was true for the mean high temperature and percentage relative humidity (Table 2). Total rainfall may indirectly promote increased psyllid and bacterial densities by increasing production of young flush shoots that are necessary for ACP reproduction and accelerated CLas multiplication (Lee et al. 2015; Sétamou and Bartels 2015). In a recent study, Shimwela et al. (2018) also reported a positive relationship between total rainfall and HLB incidence in Florida, indicating that this interaction cuts across citrus industries. The influence of the other two positively related parameters (i.e., incidences of CLaspositive ACPs and CLas titer in citrus leaf tissue) is more direct because higher CLas titers in citrus trees provide opportunities for bacterial acquisition by ACPs, and the abundance of bacteriliferous ACP populations would result in greater incidences of CLas-positive trees. Conversely, the negative relationships between the mean high temperature and percentage relative humidity on one hand and the monthly CLas incidences in citrus trees on the other may be

Table 2. Factors affecting the percentages of Diaphorina citri and citrus trees infected by Candidatus Liberibacter asiaticus (CLas) in Texas, as determined by multiple regression analysis using the best model selection method $^{\mathrm{a}}$

\begin{tabular}{|c|c|c|c|c|c|c|c|c|}
\hline CLas infection & $t$ & $P$ & $\boldsymbol{\beta}$ & $\boldsymbol{F}$ & $d f$ & $C_{p}$ & $\boldsymbol{P}$ & Adjusted $R^{2}$ \\
\hline \multicolumn{9}{|l|}{ Citrus leaf tissue } \\
\hline Overall model & & & & 16.07 & 6,65 & 4.16 & $<0.0001$ & 0.61 \\
\hline Intercept & 5.40 & $<0.0001$ & 88.74 & & & & & \\
\hline Total rainfall $(\mathrm{mm})$ & 3.16 & 0.003 & 1.80 & & & & & \\
\hline Mean high temperature $\left({ }^{\circ} \mathrm{C}\right)$ & 2.63 & 0.011 & -0.26 & & & & & \\
\hline $\mathrm{RH}(\%)$ & 6.84 & $<0.0001$ & -0.61 & & & & & \\
\hline$\%$ CLas-positive D. citri & 2.58 & 0.014 & 0.41 & & & & & \\
\hline $\begin{array}{l}\text { Cycle threshold value of CLas-positive } \\
\text { tissue }\end{array}$ & 3.18 & 0.002 & -0.55 & & & & & \\
\hline \multicolumn{9}{|l|}{ D. citri } \\
\hline Overall model & & & & 6.36 & 6,65 & 4.64 & $<0.0001$ & 0.35 \\
\hline Intercept & 2.14 & 0.037 & 15.30 & & & & & \\
\hline Wind speed $(\mathrm{km} / \mathrm{h})$ & 3.12 & 0.003 & -1.49 & & & & & \\
\hline Total rainfall $(\mathrm{mm})$ & 2.37 & 0.021 & -1.09 & & & & & \\
\hline Mean low temperature $\left({ }^{\circ} \mathrm{C}\right)$ & 2.25 & 0.028 & 0.87 & & & & & \\
\hline Heat index & 2.17 & 0.035 & -0.65 & & & & & \\
\hline \% CLas-positive Citrus trees & 2.96 & 0.005 & 0.22 & & & & & \\
\hline
\end{tabular}

${ }^{a} t=$ Student $t$-value; $P=$ probability indicating significance level of the variable; $\beta=$ regression coefficient; $F=$ Fischer's $F$-value; $d f=\operatorname{degrees~of~freedom;~} C_{p}=$ Mallows's $C_{p}$; the nearer $C_{p}$ is to the number of independent variables included in the model, the less biased is the model.

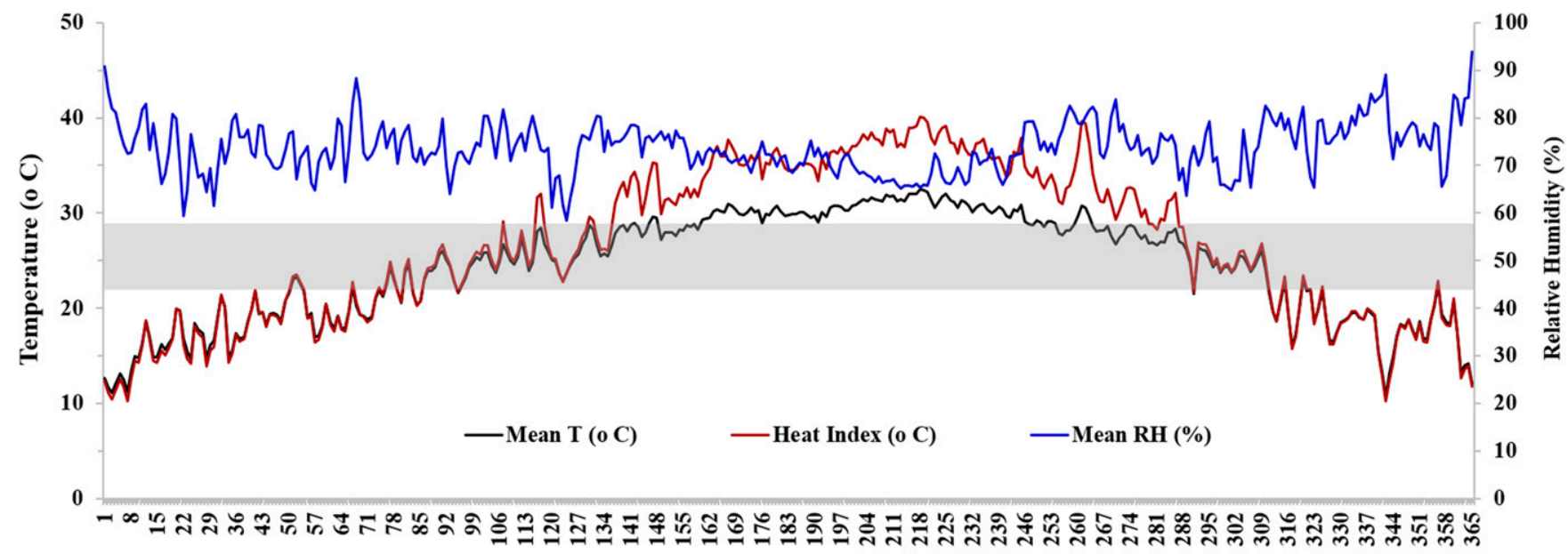

Julian days (January 2012 - December 2017)

Fig. 6. Climatic conditions prevalent in the Lower Rio Grande Valley area of south Texas, where the commercial citrus industry is located. The gray horizontal bar indicates the range of approximate optimal temperatures for the establishment of Candidatus Liberibacter asiaticus in citrus plants (Gasparoto et al. 2012) and growth and development of the Asian citrus psyllid (Liu and Tsai 2000). 
explained by the fact that extreme digits of both parameters and their prolonged durations during the growing season in the LRGV may directly affect CLas infection and establishment in trees (Gasparoto et al. 2012) and ACP growth and development (Liu and Tsai 2000) (Fig. 6). Gasparoto et al. (2018) reported that higher ambient temperatures $>27^{\circ} \mathrm{C}$ are detrimental to CLas infection of citrus trees, in line with our inference. Among the climatic factors related to the monthly CLas incidences in ACPs, a positive effect was detected for the mean low temperature, whereas wind speed, total rainfall, and the heat index showed negative effects (Table 2). Higher wind speed and rainfall may affect the settling and dispersal behavior of ACPs, thus reducing opportunities for encountering CLas-positive tissues for acquisition or new hosts for transmission. However, high heat index is detrimental to psyllid development and bacterial replication. In contrast, the mean low temperature ranges in the LRGV (20 to $26^{\circ} \mathrm{C}$ ) during active vegetative growth stages are optimal for ACP development (Hall et al. 2013), which may explain the positive relationship.

Although exponential growth was observed in the incidence of infected trees, the annual rate of increase in Texas (0.34) was slower than those reported from Florida (1.37 to 2.37) (Gottwald 2010). More than $90 \%$ of commercial groves in Texas were 15 years or older (mature groves) at the onset of the epidemics, which probably also contributed to the observed slow spread because mature trees flush less frequently and harbor fewer psyllids than younger trees (Sétamou and Bartels 2015). As previously reported, disease progress is influenced by the age of the grove at first infection (Gottwald 2010), among other factors. In addition, it is worth examining the influence of production practices on CLas/HLB progression. Unlike in Florida, citrus production in Texas is pest management intensive because the fruits are destined for the fresh market. Although ACPs were not considered a major pest in Texas before HLB detection in Florida, most pesticides targeted at other economically important arthropod pests also have efficacy on psyllids. Thus, ACP densities in Texas were generally lower than those recorded in Florida before implementation of the area-wide management program (Flores et al. 2009). There is also the possibility that the first CLas detection in Texas occurred at the onset of the epidemic.

In conclusion, this 10 -year study provided a comprehensive insight into the ongoing CLas/HLB epidemics in Texas, with potential lessons for California and other citrus-producing areas where the disease is not yet present or widespread. As grower confidence increases and new plantings are established, the current disease dynamics may be altered because of the lower median age of commercial groves. The persistence of infected trees in residential areas and

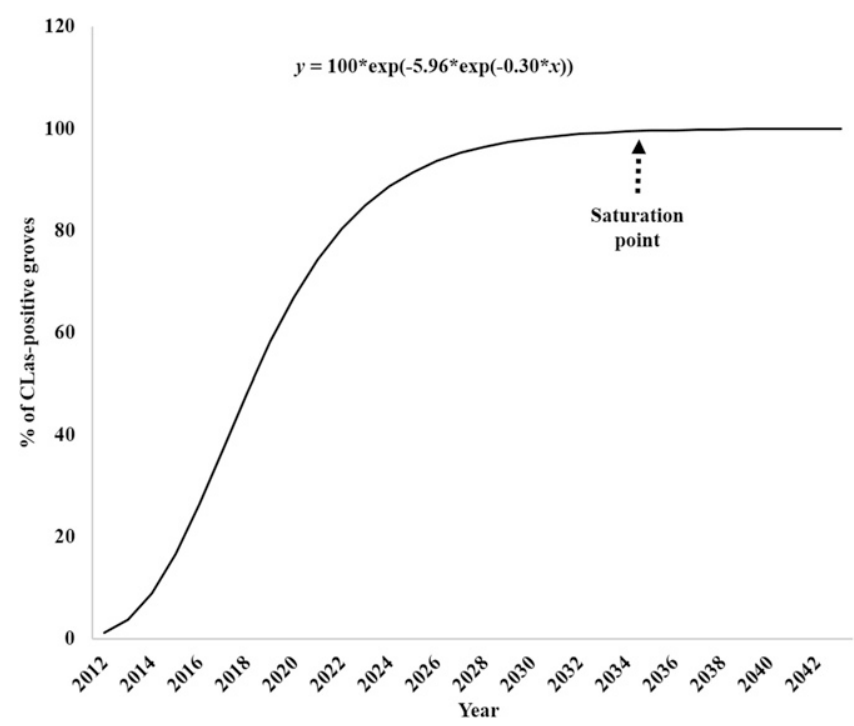

Fig. 7. A predictive model (Gompertz) of progression of the prevalence of Candidatus Liberibacter asiaticus (CLas) in commercial citrus groves in Texas. commercial groves that no longer implement tree removal may also accelerate disease spread through constant inoculum pressure. Therefore, strategies to protect new plantings from infection and the continued implementation of area-wide ACP management, including the so-called SMARTHLB approach (Sétamou and Alabi 2018), may hold the key to the sustainability of the Texas citrus industry.

\section{Acknowledgments}

We thank Robert Saldaña, James H. Hearn, and Margarita Garcia (Texas A\&M University--Kingsville Citrus Center) for technical assistance in field studies and Marissa Gonzalez and Ceasar Medelez for their contributions to the diagnostic lab work. We are also grateful to the Citrus Commodity Survey team of the U.S. Department of Agriculture Animal and Plant Health Inspection Service (USDAAPHIS) (Texas), the Texas Department of Agriculture (San Juan office), and the Texas Citrus Pest \& Disease Management Corporation (TCPDMC) for assistance with survey and sample collection. Our appreciation to the editor and two anonymous reviewers for their valuable feedback on the manuscript. This publication is dedicated to the memory of the late Maurice Duffel (USDA-APHIS Plant Protection and Quarantine) and Michael Backus (TCPDMC).

\section{Literature Cited}

Arteaga, H. C. 2017. Assessment of citrus production management in commercia groves and residential areas with special reference to HLB mitigation efforts with biological control in Texas. A thesis submitted in partial fulfilment of M.S. degree, Texas A\&M University Kingsville, pp. 47.

Alabi, O. J., Kunta, M., Dale, J., and Sétamou, M. 2014. Survey and detection of "Candidatus Liberibacter asiaticus" in a citrus nursery facility in south Texas. Plant Health Prog. 15:184-188.

Alston, K. P., and Richardson, D. M. 2006. The roles of habitat features, disturbance, and distance from putative source populations in structuring alien plant invasions at the urban/wildland interface on the Cape Peninsula, South Africa. Biol. Conserv. 132:183-198.

Ammar, E., Ramos, J. E., Hall, D. G., Dawson, W. O., and Shatters, R. G., Jr. 2016 Acquisition, replication and inoculation of Candidatus Liberibacter asiaticus following various acquisition periods on huanglongbing-infected citrus by nymphs and adults of the Asian citrus psyllid. PLoS One 11:e0159594.

Beattie, G. A. C., Holford, P., Mabberley, D. J., Haigh, A. M., and Broadbent, P. 2008. On the origins of citrus, Huanglongbing, Diaphorina citri and Trioza erytreae. Pages 25-56 in: Proceedings of the International Research Conference on Huanglongbing. https://www.plantmanagementnetwork.org/proceedings/irchlb/ 2008/Proceedings.Conference.on.HLB.2008.V14.pdf

Bové, J. M. 2006. Huanglongbing: a destructive, newly-emerging, century-old disease of citrus. J. Plant Pathol. 88:427-453.

Bové, J. M. 2014. Huanglongbing or yellow shoot, a disease of Gondwanan origin: will it destroy citrus worldwide? Phytoparasitica 42:579-583.

Coletta-Filho, H. D., Carlos, E. F., Alves, K. C. S., Pereira, M. A. R., BoscariolCamargo, R. L., de Souza, A. A., and Machado, M. A. 2010. In planta multiplication and graft transmission of 'Candidatus Liberibacter asiaticus' revealed by real-time PCR. Eur. J. Plant Pathol. 126:53-60.

da Graça, J. V. 1991. Citrus greening disease. Annu. Rev. Phytopathol. 29: 109-136.

da Graça, J. V., Douhan, G. W., Halbert, S. E., Keremane, M. L., Lee, R. F., Vidalakis, G., and Zhao, H. 2016. Huanglongbing: an overview of a complex pathosystem ravaging the world's citrus. J. Integr. Plant Biol. 58:373-387.

da Graça, J. V., French, J. V., Haslem, P. S., Skaria, M., Setamou, M., and Salas, B. 2008. Survey for the Asian citrus psyllid, Diaphoria citri, and citrus Huanglongbing (greening disease) in Texas. Subtrop. Plant Sci. 60:21-26.

da Graça, J. V., Kunta, M., Sétamou, M., Rascoe J., Li, W., Nakhla, M. K., Salas, B., and Bartels, D. W. 2015. Huanglongbing in Texas: report on the first detections in commercial citrus. J. Citrus Pathol. 2: iocv_journalcitruspathology 27939.

Flores, D., Hall, D. G., Jenkins, D. A., and Sétamou, M. 2009. Abundance of Asian citrus psyllid on yellow sticky traps in Florida, Puerto Rico, and Texas citrus groves. Southwest Entomol 34:1-11.

French, J. V., Kahlke, C. J., and da Graça, J. V. 2001. First record of the Asian citrus psylla, Diaphorina citri Kuwayama (Homoptera: Psyllidae), in Texas. Subtrop. Plant Sci. 53:14-15.

Gasparoto, M. C., Hau, B., Bassanezi, R. B., Rodrigues, J. C., and Amorim, L. 2018. Spatiotemporal dynamics of citrus huanglongbing spread: a case study Plant Pathol. 67:1621-1628.

Gasparoto, M. C. G., Coletta-Filho, H. D., Bassanezi, R. B., Lopes, S. A., Lourenço, S. A., and Amorima, L. 2012. Influence of temperature on infection and establishment of 'Candidatus Liberibacter americanus' and 'Candidatus Liberibacter asiaticus' in citrus plants. Plant Pathol. 61:658-664.

Gavier-Pizarro, G. I., Radeloff, V. C., Stewart, S. I., Huebner, C. D., and Keuler, N. S. 2010. Housing is positively associated with invasive exotic plant species richness in New England, USA. Ecol. Appl. 20:1913-1925.

Gottwald, T. R. 2010. Current epidemiological understanding of citrus huanglongbing. Annu. Rev. Phytopathol. 48:119-139. 
Grafton-Cardwell, E. E., Stelinski, L. L., and Stansly, P. A. 2013. Biology and management of Asian citrus psyllid, vector of huanglongbing pathogens. Annu. Rev. Entomol. 58:413-432.

Halbert, S. E. 2005. The discovery of huanglongbing in Florida. Pages 7-11 in: Proc. 2nd International Citrus Canker and Huanglongbing Res. Workshop, Orlando, FL, 7-11 November 2005.

Halbert, S. E., Manjunath, K., Ramadugu, C., and Lee, R. F. 2012. Incidence of huanglongbing-associated Candidatus Liberibacter asiaticus' in Diaphorina citri (Hemiptera: Psyllidae) collected from plants for sale in Florida. Fla. Entomol. 95:617-624.

Halbert, S. E., and Manjunath, K. L. 2004. Asian citrus psyllids (Sternorrhyncha: Psyllidae) and greening disease of citrus: a literature review and assessment of risk in Florida. Fla. Entomol. 87:330-353.

Hall, D. G., and Hentz, M. G. 2010. Sticky trap and stem-tap sampling protocols for the Asian citrus psyllid (Hemiptera: Psyllidae). J. Econ. Entomol. 103:541-549.

Hall, D. G., Richardson, M. L., Ammar, E. D., and Halbert, S. E. 2013. Asian citrus psyllid, Diaphorina citri, vector of citrus huanglongbing disease. Entomol. Exp. Appl. 146:207-223.

Inoue, H., Ohnishi, J., Ito, T., Tomimura, K., Miyata, S., Iwanami, T., and Ashihara, W. 2009. Enhanced proliferation and efficient transmission of Candidatus Liberibacter asiaticus by adult Diaphorina citri after acquisition feeding in the nymphal stage. Ann. Appl. Biol. 155:29-36.

Kunta, M., Sétamou, M., Skaria, M., Li, W., Nakhla, M. K., and da Graça, J. V. 2012. First report of citrus huanglongbing in Texas. Phytopathology 102:S4.66.

Lee, J. A., Halbert, S. E., Dawson, W. O., Robertson, C. J., Keesling, J. E., and Singer, B. H. 2015. Asymptomatic spread of huanglongbing and implications for disease control. Proc. Natl. Acad. Sci. 112:7605-7610.

Lewis-Rosenblum, H., Martini, X., Tiwari, S., and Stelinski, L. L. 2015. Seasonal movement patterns and long-range dispersal of Asian citrus psyllid in Florida citrus. J. Econ. Entomol. 108:3-10.

Li, W., Duan, Y., Brlansky, R. H., Twieg, E., and Levy, L. 2008b. Incidences and population of 'Candidatus Liberibacter asiaticus' in Asian citrus psyllid (Diaphorina citri) on citrus plants affected by huanglongbing in Florida. Int. Res. Conf. Huanglongbing, Dec. 1-5, 2008, Orlando, Florida.

Li, W., Hartung, J. S., and Levy, L. 2006. Quantitative real-time PCR for detection and identification of Candidatus Liberibacter species associated with citrus huanglongbing. J. Microbiol. Methods 66:104-115.
Li, W., Li, D., Twieg, E., Hartung, J. S., and Levy, L. 2008a. Optimized quantification of unculturable Candidatus Liberibacter spp. in host plants using real-time PCR. Plant Dis. 92:854-861.

Liu, Y. H., and Tsai, J. H. 2000. Effects of temperature on biology and life table parameters of the Asian citrus psyllid, Diaphorina citri Kuwayama (Homoptera: Psyllidae). Ann. Appl. Biol. 137:201-206.

Lopes, S. A., Luiz, F. Q. B. F., Oliveira, H. T., Cifuentes-Arenas, J. C., and RaiolJunior, L. 2017. Seasonal variation of 'Candidatus Liberibacter asiaticus' titers in new shoots of citrus in distinct environments. Plant Dis. 101:583-590.

Sétamou, M., and Alabi, O. J. 2018. SMART HLB ${ }^{\text {TM}}$ : an ecological approach to improve HLB management. Citrograph 9:24-27.

Sétamou, M., and Bartels, D. W. 2015. Living on the edges: spatial niche occupation of Asian citrus psyllid, Diaphorina citri Kuwayama (Hemiptera: Liviidae), in citrus groves. PLoS One 10:e0131917.

Sétamou, M., da Graça, J., and Prewett, R. 2012. HLB in Texas: steps and challenges to curb this threat. Citrograph 3:32-38.

Sétamou, M., Flores, D., French, J. V., and Hall, D. G. 2008. Dispersion patterns and sampling plans for Diaphorina citri (Hemiptera: Psyllidae) in citrus. J. Econ. Entomol. 101:1478-1487.

Shimwela, M. M., Schubert, T. S., Albritton, M., Halbert, S. E., Jones, D. J., Sun, X., Roberts, P. D., Singer, B. H., Lee, W. S., Jones, J. B., Ploetz, R. C., and van Bruggen, A. H. C. 2018. Regional spatial-temporal spread of citrus huanglongbing is affected by rain in Florida. Phytopathology 108: 1420-1428.

Singerman, A., Lence, S. H., and Useche, P. 2017. Is area-wide pest management useful? The case of citrus greening. Appl. Econ. Perspect. Policy 39:609-634.

Timmer, L. W., Garnsey, S. M., and Graham, J. H. 2000. Compendium of Citrus Diseases, 2nd ed. Diseases and Pests Compendium Series. American Phytopathological Society, St. Paul, MN.

United States Department of Agriculture, National Agricultural Statistics Service. 2016. Florida Citrus Statistics 2014-2015. U.S. Department of Agriculture National Agricultural Statistics Service, Washington, DC.

Velásquez, A. C., Castroverde, C. D. M., and He, S. Y. 2018. Plant-pathogen warfare under changing climate conditions. Curr. Biol. 28:R619-R634.

XLSTAT. 2017. Data Analysis in Statistical Solution for Microsoft Excel. Addinsoft, Paris, France. 